\title{
Improvement of left ventricular remodeling after myocardial infarction with eight weeks L-thyroxine treatment in rats
}

\author{
Yue-Feng Chen ${ }^{1,3}$, Nathan Y Weltman ${ }^{2}$, Xiang Li ${ }^{1}$, Steven Youmans ${ }^{1}$, David Krause ${ }^{2}$ and Anthony Martin Gerdes ${ }^{1 *}$
}

\begin{abstract}
Background: Left ventricular (LV) remodeling following large transmural myocardial infarction (MI) remains a pivotal clinical issue despite the advance of medical treatment over the past few decades. Identification of new medications to improve the remodeling process and prevent progression to heart failure after $\mathrm{Ml}$ is critical. Thyroid hormones (THs) have been shown to improve LV function and remodeling in animals post-MI and in the human setting. However, changes in underlying cellular remodeling resulting from TH treatment are not clear.

Methods: MI was produced in adult female Sprague-Dawley rats by ligation of the left descending coronary artery. L-thyroxine (T4) pellet (3.3 mg, 60 days sustained release) was used to treat MI rats for 8 weeks. Isolated myocyte shape, arterioles, and collagen deposition in the non-infarcted area were measured at terminal study.

Results: T4 treatment improved LV $\pm d p / d t$, normalized TAU, and increased myocyte cross-sectional area without further increasing myocyte length in MI rats. T4 treatment increased the total LV tissue area by $34 \%$, increased the non-infarcted tissue area by $41 \%$, and increased the thickness of non-infarcted area by $36 \%$ in Ml rats. However, myocyte volume accounted for only $\sim 1 / 3$ of the increase in myocyte mass in the non-infarct area, indicating the presence of more myocytes with treatment. T4 treatment tended to increase the total length of smaller arterioles (5 to $15 \mu \mathrm{m}$ ) proportional to LV weight increase and also decreased collagen deposition in the LV non-infarcted area. A tendency for increased metalloproteinase-2 (MMP-2) expression and tissue inhibitor of metalloproteinases (TIMPs) -1 to -4 expression was also observed in T4 treated MI rats.

Conclusions: These results suggest that long-term T4 treatment after MI has beneficial effects on myocyte, arteriolar, and collagen matrix remodeling in the non-infarcted area. Most importantly, results suggest improved survival of myocytes in the peri-infarct area.
\end{abstract}

Keywords: Thyroid hormone, Myocardial infarction, Myocyte, Arteriole, Collagen

\section{Introduction}

Left ventricular (LV) remodeling after myocardial infarction (MI) includes infarct expansion and hypertrophy of non-infarcted myocardium, fibrosis, LV chamber dilatation, LV functional deterioration and progression to heart failure [1-3]. The underlying cellular mechanism for maladaptive hypertrophy of the non-infarcted area includes progressive myocyte lengthening without a proportional increase in myocyte cross-sectional area $[4,5]$.

\footnotetext{
* Correspondence: agerdes@nyit.edu

'Department of Biomedical Sciences, NYIT College of Osteopathic Medicine, New York Institute of Technology, Old Westbury, NY 11568, USA

Full list of author information is available at the end of the article
}

Treatments targeting the remodeling process, such as beta-blockers and angiotensin converting enzyme inhibitors, have been shown to improve LV function as well as long-term survival. However, slow progression to chronic heart failure continues with large transmural MI as the loss of infarcted tissue and volume overload (chamber dilation) is often out of proportion to the hypertrophic response. Thus, searching for new medications that can further improve the remodeling process is critical for preventing heart failure following MI.

"Low T3 syndrome" is commonly found in patients with acute MI and other serious medical conditions. A strong association between restoration of serum T3

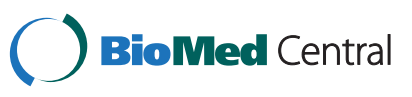


levels and recovery of cardiac function in patients following MI suggests that thyroid hormones play a critical role in the extent of cardiac dysfunction [6]. Animal studies have also confirmed that low thyroid status existed for up to 12 weeks following MI $[7,8]$. Our group has shown that treatment with triiodothyronine (T3) reduces myocyte apoptosis in the MI border area shortly after MI [9]. Based on echocardiographic measurements, other researchers also showed that longer thyroid hormone $(\mathrm{TH})$ treatment can improve LV function and LV remodeling [10-12]. TH treatment promoted a beneficial change in myocyte shape in an animal model of hypertension/heart failure leading to a reduction in LV wall stress and improved function [13]. However, the effects of long-term $\mathrm{TH}$ treatment on myocyte remodeling following MI are unknown.

THs have been shown to induce capillary and arteriolar growth in the hypertrophic heart $[14,15]$. Whether they can improve arteriolar growth in the infarcted heart is unknown. Increased collagen deposition in both the infarcted and non-infarct regions is an important component of the LV remodeling process after MI. Others have reported that $\mathrm{THs}$ can inhibit collagen production in vivo and in vitro $[16,17]$. But, $\mathrm{TH}$ effects on collagen remodeling after $\mathrm{MI}$ are uncertain.

In this study, we used a MI model produced by coronary ligation in adult female Sprague-Dawley rats and treated the animals with L-thyroxine (T4) after surgery for 8 weeks. The purpose of the study was to confirm whether or not post-MI T4 treatment leads to improved LV remodeling of myocytes, arterioles, and collagen.

\section{Materials and methods}

\section{Preliminary experiments}

Neither the form (T3 or T4) nor an optimum administration approach for chronic treatment of animal models of cardiac disease with THs has been established. In these experiments, we employed slow-release pellets implanted subcutaneously. Pellets containing three different T3 and T4 doses each were implanted in a minimum of 5 rats per group after surgical production of MI. All rats were examined at one month post-MI. The goal was to identify a pellet dose that produced maximum improvement of $\mathrm{LV}$ function and improved remodeling of isolated myocyte shape with a detectible, but insignificant increase in heart rate. While the selected pellet dose would likely be too high for long-term therapy, the goal was to identify the maximum treatment benefits. The highest T3 and T4 pellet doses were well tolerated and did not lead to mortality but produced excessive tachycardia and were not considered further. Others produced no detectible effects. A $3.3 \mathrm{mg} 60$ day sustained release T4 pellet best matched selection criteria and was selected for future experiments.

\section{Experimental design}

Adult female Sprague-Dawley rats aged 12 weeks old were used in this study. MI was produced by ligation of the left descending coronary artery [18]. Immediately following this procedure, MI survivors were randomly assigned to (1) MI group $(n=24)$ and (2) MI+T4 group $(n=23)$. A (3) Sham-MI group $(n=21)$ was produced with a similar procedure except that the suture was tied loosely around the coronary artery. Thus, three groups comprised the study. T4 pellets (Innovative Research of America, Sarasota, FL; $3.3 \mathrm{mg}, 60$ days sustained release) were implanted subcutaneously into the MI+T4 group and placebo pellets were implanted into the MI and Sham-MI groups respectively immediately after surgery. Animals were housed two per cage and kept on a $12 \mathrm{~h}$ light/dark cycle with food and water provided ad libitum. At termination, cardiac function was assessed by echocardiography and LV catheterization for each animal in the study. All experiments and protocols were performed in accordance with the Guide for the Care and Use of Laboratory Animals (US Department of Health, Education, and Welfare, Department of Health and Human Services, NIH Publication 85-23), and approved by the University of South Dakota Animal Care and Use Committee.

\section{Echocardiographic measurements}

A Visualsonics 660 imaging system with a $20 \mathrm{MHz}$ transducer (Toronto, Canada) was used to perform echocardiography on each rat before euthanasia [19]. The rat was anesthetized under $1.5 \%$ isoflurane and two-dimensional echocardiograms were obtained from short-axis views of the left ventricle at the level of the papillary muscle tips. Two-dimensionally targeted M-mode echocardiograms were used to measure the LV dimensions in systole and diastole.

\section{Cardiac hemodynamic measurements}

LV hemodynamics were measured with a Millar Microtip catheter (Millar Instruments; Houston, TX) through catheterization of the right carotid [4]. Data were recorded using an MPVS-400 Pressure-Volume System (Millar Instruments; Houston, TX). The following data were collected: heart rate (HR), LV peak systolic pressure (LVSP), LV end-diastolic pressure (LVEDP), positive/negative change in pressure over time $(d p / d t)$, and TAU (time constant of isovolumic relaxation).

\section{Myocyte isolation}

The rats in each group were separated into two groups, one for myocyte isolation and the other for whole heart tissue collection. For each MI animal, circumferential infarct length was measured just below the suture using an electronic caliper when the chest was opened. 
Table 1 Changes in body weight, heart weight, and infarct size

\begin{tabular}{lcccccc}
\hline & N & Body Wt1 (gm) & Body Wt2 (gm) & Heart Wt (mg) & Hw/BWt2 (mg/gm) & Infarct length (mm) \\
\hline Sham & 21 & $239(19)$ & $269(23)$ & $824(70)$ & $3.1(0.3)$ & \\
MI & 24 & $236(23)$ & $273(30)$ & $936(93)^{* *}$ & $3.5(0.4)^{* *}$ & $10.3(0.8)$ \\
MI+T4 & 23 & $230(20)$ & $272(25)$ & $1202(200)^{* *} \neq$ & $4.4(0.7)^{* *} \neq$ & $10.7(1.1)$ \\
$\%$ (MI+T4 vs. Ml) & & -3 & -0.3 & 28 & 26 & 4 \\
\hline
\end{tabular}

Data presented as means (SD).

$\mathrm{N}$, total number of rats (both preps); Body Wt1, body weight before surgery; Body wt2, body weight at terminal study. Heart Wt, heart weight; Hw/BWt2, heart wtto-body wt2 ratio; ${ }^{*}, p<0.05,{ }^{* *}, p<0.01$ vs. Sham rats; $\neq, p<0.01$ vs. MI rats; ANOVA with Student-Newman-Keuls' or Dunnett T3's (Heart Wt and Hw/BWt2) Multiple Comparison Test.

Cardiac myocytes were isolated using a standard procedure [20]. After hemodynamic measurement, animal was deeply anesthetized, the chest was opened, and the heart was quickly removed, blotted, and weighed. The aorta was cannulated for retrograde perfusion with calcium-free Joklik media at $37^{\circ} \mathrm{C}$ followed by media containing $0.1 \%$ collagenase (Worthington Biomedical Corp., Lakewood, NJ). After collagenase perfusion, LV non-infarcted area + septum was separated, minced in calcium-free Joklik media, and isolated cells were poured through nylon mesh $(250 \mu \mathrm{m})$ into $2 \%$ glutaraldehyde for cell size measurements.

\section{Whole heart tissue collection}

After hemodynamic data were collected, the chest was opened and the heart was arrested in diastole by injection of saturated potassium chloride solution via the inferior vena cava.

The heart was then removed and cannulated through the aorta with an 18 gauge gavage needle, perfused with ice cold PBS, and subsequently trimmed, blotted, and weighed. The LV plus septum and the right ventricle (RV) were dissected and weighed. LVs were then cut into 3 pieces transversely, perpendicularly to the LV long axis. The middle slice, which was cut $1 \mathrm{~mm}$ below the suture, was immersion fixed in $4 \%$ paraformaldehyde for $24 \mathrm{~h}$, then embedded in paraffin, and sectioned at $5 \mu \mathrm{m}$ thickness for immunohistochemistry analysis. The basal and apical slices were frozen in liquid nitrogen and stored in $-80^{\circ} \mathrm{C}$ until used.

\section{Determination of cellular dimensions of isolated myocytes}

Myocytes isolated from LV non-infarcted area + septum were measured. Cell volume (V) was determined with a Coulter Channelyzer [21]. Cell length (L) of randomly selected undamaged myocytes was measured directly using microscopy and an Image-Pro Plus analysis system (Media Cybernetics, Inc., Bethesda, MD; 50 cells per sample). Cross-sectional area was calculated by dividing cell volume by cell length.

\section{Arteriolar staining and quantification}

Paraformaldehyde fixed LV tissue sections were used. Combined Isolectin B4 (IB4, marker of endothelial cells, ECs) and $\alpha$-smooth muscle actin ( $\alpha$-SMA, immunohistochemical marker of smooth muscle cells) labeling was used to identify arterioles. After deparaffinization, rehydration and heat-induced antigen retrieval, tissue sections were stained with FITC-conjugated IB4 (IB4-FITC; Vector Labs, Burlingame, CA; final dilution 1:200) and Cy3-conjugated $\alpha-S M A$ antibody ( $\alpha-S M A-C y 3$; Sigma, St. Louis, MO; final dilution 1:5000) in 2\% BSA in TBS$\mathrm{T}-\mathrm{Ca} 2+$ for one hour, rinsed with TBS-T-Ca2+, and coverslipped with Fluoromount G (EMS, Hatfield, PA). All fluorescence images were acquired using an Olympus FluoView 1000 (FV1000) confocal laser scanning microscope (Olympus Corp., Tokyo, Japan). Myocardial arterioles were visualized by confocal microscopy at $20 \mathrm{x}$ magnification. On the basis of the minor diameter, arterioles between 5 and $30 \mu \mathrm{m}$ with at least one layer of

Table 2 Changes in body weight, heart weight, and infarct size (whole heart tissue preps)

\begin{tabular}{lcccccccc}
\hline & N & Body Wt1 (gm) & Body Wt2 (gm) & Heart Wt $(\mathbf{m g})$ & Hw/BWt2 (mg/gm) & LV Wt (mg) & RV Wt (mg) & Infarct length (mm) \\
\hline Sham & 9 & $253(10)$ & $268(15)$ & $762(50)$ & $2.8(0.1)$ & $563(40)$ & $138(15)$ & \\
MI & 10 & $249(23)$ & $268(19)$ & $906(90)^{* *}$ & $3.4(0.6)^{*}$ & $594(63)$ & $205(75)$ & $10.5(0.7)$ \\
Ml+T4 & 9 & $243(15)$ & $285(22)$ & $1217(135)^{* *} \neq$ & $4.3(0.3)^{* *} \neq$ & $793(185)^{*}$ & $304(68)^{* *}+$ & $11.0(0.7)$ \\
$\%($ MI+T4 vs. MI) & -2 & 6 & 34 & 26 & 34 & 48 & 5 \\
\hline
\end{tabular}

Data presented as means (SD).

$\mathrm{N}$, total number of rats for whole heart tissue collection; Body Wt1, body weight before surgery; Body wt2, body weight at terminal study; Heart Wt, heart weight; $\mathrm{Hw} / \mathrm{BWt2}$, heart wt-to-body wt2 ratio; LV Wt, left ventricular weight; $\mathrm{RV} W \mathrm{Wt}$, right ventricular weight; ${ }^{*}, p<0.05, * *, p<0.01 \mathrm{vs}$. Sham rats; $\dagger, p<0.05, \neq, p<0.01 \mathrm{vs}$. MI rats; ANOVA with Student-Newman-Keuls' or Dunnett T3's (Heart Wt, Hw/BWt2, LV Wt and RV Wt) Multiple Comparison Test. 
Table 3 Serum T3 and T4 levels

\begin{tabular}{llcc}
\hline & $\mathbf{N}$ & Total T3 $(\mathbf{n g} / \mathbf{m l})$ & Total T4 $(\mathbf{n g} / \mathbf{m l})$ \\
\hline Sham & 10 & $2.2(0.3)$ & $30.8(9.8)$ \\
Ml & 13 & $2.2(0.4)$ & $37.3(10.0)$ \\
Ml+T4 & 13 & $2.9(1.3)$ & $55.3(11.4)^{* *} \neq$ \\
\hline
\end{tabular}

Data presented as means (SD). N, total number of rats assayed.

** $p<0.01$ vs. Sham operated rats; $\neq, p<0.01$ vs. MI rats;

ANOVA with Student-Newman-Keuls' Multiple Comparison Test.

smooth muscle were classified and length density (LD) determined from each animal. Arteriolar LD (average length of arterioles/unit myocyte volume) was calculated based on the following formula: $\mathrm{LD}\left(\mathrm{mm} / \mathrm{mm}^{3}\right)=\Sigma(a /$ $b) / \mathrm{M}$, where $a$ and $b$ are the maximum and minimum external arteriolar diameters, respectively, and $M$ is the solid tissue area [22]. Arteriolar LD was converted to total arteriolar length by multiplying $\mathrm{LD}(\mathrm{mm} / \mathrm{mm} 3)$ by LV weight expressed in $\mathrm{mm}^{3}$ ( 1 $\mathrm{mg}$ of cardiac tissue is equivalent to $1 \mathrm{~mm}^{3}$ ).

\section{Masson's Trichrome staining}

Paraformaldehyde fixed LV tissue sections were stained with Trichrome at the Histology Core of SanfordBurnham Institute for Medical Research (La Jolla, CA). High resolution images were obtained through Aperio Scanscope software (Burnham Institute, La Jolla, CA) and cardiac fibrosis was quantified using Image-Pro plus (Media Cybernetics, Bethesda, MD).

\section{ELISA}

Blood samples were drawn from opened chests via the inferior vena cava and separated into serum aliquots by centrifugation and stored at $-70^{\circ} \mathrm{C}$ until assayed. Serum T3 and T4 levels were measured using ELISA kits according to the manufacturers' specification. T3 and T4 kits were obtained from Monobind Inc. (human kit, Lake Forest, CA).

\section{Real-time quantitative PCR for gene expression}

RNA from 50-100 mg of the basal part of left ventricles was extracted using the PureLink ${ }^{\mathrm{TM}}$ RNA Mini Kit (Invitrogen, Carlsbad, CA). Oligo (dT) primed cDNA synthesis was performed using $\mathrm{RT}^{2}$ First Strand kit (SABiosciences, Frederick, MD). Levels of $\alpha M H C, \beta M H C$, MMP-2, TIMP-
1, TIMP-2, TIMP-3 and TIMP-4 mRNAs were measured by real-time quantitative RT-PCR using the $\mathrm{RT}^{2} \mathrm{SYBR}^{\circledR}$ Green qPCR Mastermixes with validated primers (Qiagen, Inc., Valencia, CA) and the Applied Biosystem StepOnePlus ${ }^{\text {TM }}$ real-time PCR system and software (version 2.2; Life Technologies, Carlsbad, California). For RT-PCR reactions $(20 \mu \mathrm{l})$, equal amounts $(500 \mathrm{ng})$ of total RNA were used. Expression data were analyzed using SABiosciences expression analysis template in Excel (Microsoft Office 2010). The level of expression was calculated as fold change compared to sham-MI or MI control using the Ct value after normalizing with the PPIA and RPLP.

\section{Statistical analysis}

All data are expressed as means (SD) and were compared using a two-tailed Student's $t$-test or one-way ANOVA. In addition, a Student-Newman-Keuls or Dunnett T3 (Equal variances not assumed) post-hoc test was used to examine significant differences between groups. A value of $\mathrm{P}<0.05$ was considered statistically significant.

\section{Results}

\section{Effects of T4 on heart weight and body weight}

Average body weights, heart weights, and heart weightto-body weight ratios are shown in Tables 1 and 2. Compared to the sham-MI group, both MI groups had significantly increased heart weight and heart weightto-body weight ratios. T4 treatment significantly increased heart weight, heart weight-to-body weight ratio, and LV weight (increased by $28 \%, 26 \%$ and $34 \%$, respectively) in MI animals compared to untreated MI animals. There were no significant differences in body mass among these 3 groups before surgery and at terminal experiments. MI rats with small infarcts less than $7 \mathrm{~mm}$ were excluded from this study. Only 2 rats in the treatment group were excluded. The average infarct length for the remaining rats was similar in both MI groups.

\section{Changes of serum T3 and T4 levels after T4 treatment}

Serum T3 and T4 levels are shown in Table 3. No difference was found in serum T3 and T4 levels between MI and sham-operated groups. Treatment with T4 significantly increased serum T4 levels, and tended to increase

Table 4 Echocardiographic data

\begin{tabular}{|c|c|c|c|c|c|c|c|c|c|}
\hline & $\mathrm{N}$ & Heart rate (beats/min) & IVSd (mm) & IVSs (mm) & LVIDd (mm) & LVIDs (mm) & LVPWd (mm) & LVPWs (mm) & FS (\%) \\
\hline Sham & 18 & $342(29)$ & $1.3(0.3)$ & $2.3(0.4)$ & $7.1(0.4)$ & $4.2(0.7)$ & $1.7(0.4)$ & $2.6(0.5)$ & $40.7(8.9)$ \\
\hline Ml & 19 & $342(26)$ & $1.2(0.4)$ & $1.9(0.6)^{*}$ & $9.2(0.8)^{* *}$ & $7.2(0.8)^{* *}$ & $1.5(0.3)$ & $1.9(0.5)^{* *}$ & $22.4(4.9)^{* *}$ \\
\hline $\mathrm{Ml}+\mathrm{T} 4$ & 20 & $400(68)^{* *} \neq$ & $1.5(0.5) \dagger$ & $2.3(0.6)$ & $9.9(0.8)^{* *}$ & $7.6(1.1)^{* *}$ & $1.7(0.6)$ & $2.0(0.6)^{* *}$ & $23.6(6.2)^{* *}$ \\
\hline
\end{tabular}

Data presented as means (SD).

IVSd and IVSs, interventricular septal thickness in end diastole and systole, respectively; LVIDd and LVIDs, left ventricular diastolic and systolic internal diameter, respectively; LVPWd and LVPWs, left ventricular diastolic and systolic posterior wall thickness, respectively; FS, fractional shortening; ${ }^{* *}, p<0.01$ vs. Sham rats; $\dagger$, $p<0.05, \neq, p<0.01$ vs. MI rats; ANOVA with Student-Newman-Keuls' or Dunnett T3's (LVIDd, LVIDs and LVPWd) Multiple Comparison Test. 
Table 5 Hemodynamic data

\begin{tabular}{|c|c|c|c|c|c|c|c|}
\hline & $\mathrm{N}$ & Heart rate (beats/min) & LVSP $(\mathrm{mmHg})$ & LVEDP $(\mathrm{mmHg})$ & $+d p / d t(\mathrm{mmHg} / \mathrm{sec})$ & $-d p / d t \quad(\mathrm{mmHg} / \mathrm{sec})$ & TAU (msec) \\
\hline Sham & 19 & $343(41)$ & $124(14)$ & $4.5(1.2)$ & $8626(1830)$ & $9958(2373)$ & $10.2(2.3)$ \\
\hline $\mathrm{Ml}$ & 16 & $335(48)$ & $113(14)$ & $6.1(2.0)^{*}$ & $6768(1465)^{* *}$ & $5624(1232)^{* *}$ & $13.7(2.2)^{* *}$ \\
\hline $\mathrm{Ml}+\mathrm{T} 4$ & 17 & 393(74)† & $127(22)$ & $5.9(1.9)^{*}$ & $8862(2746)+$ & $7058(1987)^{* *} \dagger$ & 10.8(2.0)‡ \\
\hline
\end{tabular}

Data presented as means (SD).

LVSP and LVEDP, left ventricular end-systolic and end-diastolic pressure, respectively; $+d p / d t$ and $-d p / d t$, maximal rate of pressure development and decline, respectively; ${ }^{*}, p<0.05,{ }^{* *}, p<0.01$ vs. Sham rats; $\dagger, p<0.05, \neq, p<0.01$ vs. MI rats; ANOVA with Student-Newman-Keuls' or Dunnett T3's (Heart rate, LVSP and $+d p / d t$ ) Multiple Comparison Test.

serum T3 levels but did not reach statistical significance as compared with MI and sham-MI groups.

\section{Echocardiographic changes after T4 treatment}

Table 4 shows echocardiographic data. Compared with sham-MI animals, MI resulted in significantly increased LV chamber dimension during systole and diastole, decreased LV posterior wall thickness during systole, and decreased fractional shortening. No changes of the above-mentioned indices were seen with T4 treatment except for a slight but significant increase in heart rate, and a tendency for increased inter-septal thickness, which did not reach statistical significance.

\section{Effects of T4 on LV hemodynamics}

Hemodynamic data are summarized in Table 5. MI caused a significant decrease in $+d p / d t$ and $-d p / d t$, as well as an increase in LV end-diastolic pressure and TAU as compared with the sham-MI animals. T4 treatment led to an increase in $\pm d p / d t$ and heart rate, as well as a decrease in TAU in MI animals compared to untreated MI animals, resulting in a normalization of $+d p /$ $d t$ and TAU. No change in LVEDP was seen with T4 treatment as compared with the untreated MI group.

\section{T4 Induced beneficial changes in myocyte shape on} myocytes isolated from the non-infarcted myocardium Table 6 shows myocyte measurements. MI induced an increase in myocyte volume and length as compared with sham-MI animals. T4 treatment resulted in a further increase in myocyte volume (13\% increase) due exclusively to an increase in myocyte cross-sectional area but no further increase in myocyte length as compared with untreated MI animals.

\section{Changes in left ventricular perimeters and tissue areas with T4 treatment}

LV perimeter and tissue area measurements are presented in Tables 7 and 8 respectively. No significant difference was found in the inner and outer perimeters of LV, non-infarct area, and infarcted area between MI and MI+T4 groups. There was no significant difference in the percentage infarct size between these two groups either.

Compared to the untreated MI group, the MI+T4 group had a significant increase in total LV tissue area (34\% increase), especially the non-infarct tissue area $(41 \%$ increase), as well as the thickness of both infarcted and non-infarct area (30\% and 36\% increase, respectively).

\section{The effects of T4 on arteriolar remodeling in the LV non-} infarcted area after MI

In smaller arterioles $(5-15 \mu \mathrm{m})$, no change in length density was found in MI rats regardless of T4 treatment (Figure 1a), however, the total length (length density $x$ LV weight) tended to have a stepwise increase with the LV weight increase in MI and T4 treated MI hearts (Figure 1b). No changes in length density and total length were found in larger arterioles $(15-30 \mu \mathrm{m})$ with MI regardless of T4 treatment. Consequently, growth was in small, rather than larger arterioles.

Table 6 LV myocyte dimensions

\begin{tabular}{|c|c|c|c|c|}
\hline Groups & $\mathbf{N}$ & Cell volume $\left(\mu \mathrm{m}^{3}\right)$ & Cell length $(\mu \mathrm{m})$ & $\mathrm{CSA}(\mu \mathrm{m})$ \\
\hline Sham & 10 & $31516(3484)$ & $131.4(3.9)$ & $240(26)$ \\
\hline $\mathrm{Ml}$ & 11 & $36894(3288)^{* *}$ & $151.4(6.2)^{* *}$ & $244(19)$ \\
\hline $\mathrm{Ml}+\mathrm{T} 4$ & 10 & $41818(4117)^{* *} \neq$ & $151.9(5.6)^{* *}$ & $275(28)^{* *} \neq$ \\
\hline$\%(\mathrm{Ml}+\mathrm{T} 4$ vs. MI) & & 13 & 0.3 & 13 \\
\hline
\end{tabular}

Data presented as means (SD). N, number of rats, isolated myocyte preps;

CSA, cross-sectional area; values for cell length normalized to $1.90 \mu \mathrm{m}$ (resting unloaded sarcomere length).

**, $p<0.01$ vs. Sham rats; $\dagger, p<0.05, \ddagger, p<0.01$ vs. Ml rats;

ANOVA with Student-Newman-Keuls' Multiple Comparison Test. 
Table 7 LV areas

\begin{tabular}{llllllll}
\hline Groups & $\begin{array}{l}\mathbf{N} \\
\left(\mathbf{m m}^{2}\right)\end{array}$ & $\begin{array}{l}\text { Total tissue area } \\
\left(\mathbf{m m}^{2}\right)\end{array}$ & $\begin{array}{l}\text { Non-infarct area } \\
\left(\mathbf{m m}^{2}\right)\end{array}$ & $\begin{array}{l}\text { Ml area } \\
(\mathbf{m m})\end{array}$ & $\begin{array}{l}\text { Infarct thickness } \\
(\mathbf{m m})\end{array}$ & $\begin{array}{l}\text { MI area/Total tissue } \\
\text { area }\end{array}$ \\
\hline $\mathrm{Ml}$ & 9 & $38.9(4.6)$ & $27.4(4.5)$ & $11.5(2.8)$ & $1.93(0.36)$ & $0.97(0.23)$ & $0.30(0.07)$ \\
$\mathrm{MI+T4}$ & 9 & $52.2(12.9)^{* *}$ & $38.6(10.6)^{* *}$ & $13.6(4.2)$ & $2.62(0.99)^{*}$ & $1.26(0.33)^{*}$ & $0.27(0.08)$ \\
$\%$ & 34 & 41 & 18 & 36 & 30 & -10 \\
\hline
\end{tabular}

Data presented as means (SD). N, number of rats; ${ }^{*}, p<0.05,{ }^{* *}, p<0.01$ vs. MI rats; Independent Samples Student's $t$-Test.

The effect of T4 on collagen deposition in the LV noninfarcted area after MI

Collagen deposition in the LV non-infarcted area was increased with MI as compared to the sham-MI group. There was a tendency for reduction of collagen content with T4 treatment in MI animals but this did not reach statistical significance (Table 9, Figure 2).

The effect of TH on the expression of MHCs, MMPs and TIMPs in the LV non-infarcted area after MI

Compared to sham-MI rats, MI caused an increase in $\beta M H C$, MMP-2 and TIMPs -1 to -4 expressions, and a decrease in $\alpha \mathrm{MHC}$ gene expression. These changes were partially reversed by T4 treatment except for MMP-2, where T4 treatment tended to further increase its expression. Again, these changes did not reach statistical significance (Table 10).

\section{Discussion}

The T4 dose used for this study was chosen based on preliminary experiments testing several different doses of T3 and T4. A consistent beneficial effect on LV function and myocyte remodeling with a slight (borderline significant) increase in heart rate was observed with this particular dose. This dose was well tolerated by the MI rats where only 1 animal in the treatment group died after 2 days of treatment during the entire experiment (consistent with a surgical-related death). In this study, eight weeks of T4 treatment after MI significantly increased serum T4 levels and tended to increase serum T3 levels, with a reversal of the $\alpha$ - and $\beta$-MHC gene expression patterns caused by MI. T4 treatment increased heart weight, especially LV weight, heart weight-body weight ratio, and $\mathrm{LV} \pm d p / d t$, while normalizing TAU. Myocytes isolated from the non-infarcted myocardium showed significant lengthening with $\mathrm{MI}$, and T4 treatment enhanced myocyte cross-sectional area without further increased myocyte length. There was a significant increase (34\% increase) in total LV tissue area, especially in the non-infarcted tissue area (41\% increase), as well as an increase in the thickness of both infarcted and noninfarcted areas (30\% and 36\% increase, respectively) in MI rats treated with $\mathrm{T} 4$. The total length of smaller arterioles ranging from 5 to $15 \mu \mathrm{m}$ tended to increase, and collagen deposition tended to decrease with $\mathrm{T} 4$ treatment in the LV non-infarcted area.

Many studies have shown that either short term or long term treatment with THs starting early or late after MI can improve LV function and gross measures of LV remodeling $[9,10,12,23,24]$. The present study confirmed that 8 weeks of T4 treatment initiated immediately following MI can improve LV cardiac contractility and relaxation. Although no changes in LV dimension and wall thickness were appreciated with echocardiography in the present study, an increase in LV non-infarcted area thickness was found with T4 treatment in the MI rats by direct measurement of LV tissue cross-sections. In addition, myocytes isolated from LV non-infarcted myocardium were found to have an increase in cell volume after MI due exclusively to cell lengthening, which is consistent with our previous reports from rats and humans $[4,5,25]$. An increase in cross-sectional area without further cell lengthening was found in myocytes isolated from the same area with $\mathrm{T} 4$ treatment, which further increased the cell volume. This selective growth in myocyte transverse area from $\mathrm{TH}$ treatment is similar to results from our previous study in Spontaneous Hypertensive Heart Failure rats [13] but has never been reported in the MI model. Increased myocyte crosssectional area contributed to increased wall thickness in the LV non-infarcted area with T4 treatment, a change that should reduce wall stress and improve LV function. It should be noted that T4 treatment led to only a $13 \%$ increase in cell volume (exclusively from increased cross-sectional area), which cannot account for the $34 \%$ increase in LV weight and the $41 \%$ increase in the non-

Table $8 \mathrm{LV}$ perimeters

\begin{tabular}{llllll}
\hline Groups & N & LV perimeter $(\mathbf{m m})$ & Non-infarct perimeter $(\mathbf{m m})$ & Ml perimeter $(\mathbf{m m})$ & Infarct size $(\%)$ \\
\hline Ml & 9 & $26.4(2.7)$ & $14.4(2.7)$ & $11.9(1.2)$ & $46(5)$ \\
MI+T4 & 9 & $26.4(4.1)$ & $15.5(3.4)$ & $10.9(2.0)$ & $42(7)$ \\
$\%$ & & 0 & 7.6 & -8 & -9 \\
\hline
\end{tabular}

Data presented as means (SD). N, number of rats. Perimeter $=$ (outer perimeter + inner perimeter) $/ 2$. 


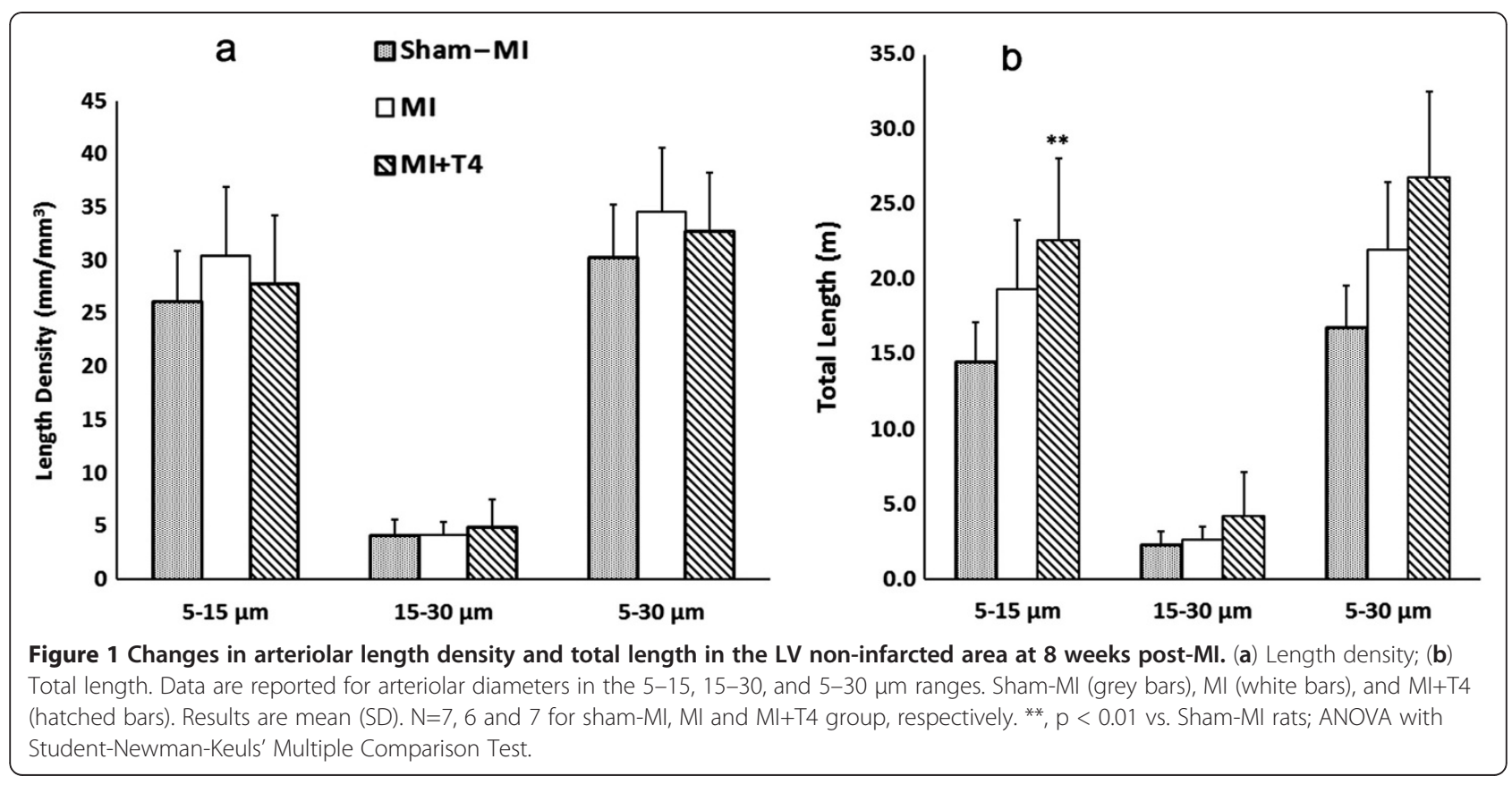

infarct tissue area. Since the Coulter Channelyzer method offers precise measurements of isolated myocyte volume when high quality cells are assessed and whole tissue changes can also be precisely collected, these combined data indicate that more myocytes were present in the non-infarct area with $\mathrm{T} 4$ treatment as compared to untreated MI rats. This finding, that isolated myocyte volume accounted for only $\sim 1 / 3$ of the increase in muscle mass from $\mathrm{TH}$ treatment, was consistently observed in other preliminary experiments. We previously reported that $\mathrm{TH}$ treatment immediately following MI reduced the expression of markers of apoptosis in myocytes in the border area [9]. New data provided here suggest that the previously observed $\mathrm{TH}-$ mediated inhibition of apoptosis led to increased preservation of myocyte number in the border zone of the non-infarcted tissue area.

Small arterioles are very important for myocardium perfusion and oxygen supply. The pro-angiogenic effect of THs has been demonstrated in different models in which the growth of capillaries and arterioles were observed $[14,15,26]$. A stepwise increase in the total length of smaller arterioles ( 5 to $15 \mu \mathrm{m}$ ) was found following MI and T4 treatment, indicating a parallel growth of small arterioles along with myocyte hypertrophy, which would help maintain blood supply to the hypertrophic heart.

Increased collagen deposition observed in the noninfarcted area here was also found by others [27,28]. Eight weeks T4 treatment following MI tended to decrease collagen deposition in the non-infarct area, which might contribute to the improvement of LV relaxation.
The anti-fibrotic effect of TH has been documented in culture conditions as well as in TH-induced hypertrophic hearts which was mediated by either decreased collagen production or increased collagen degradation $[16,29,30]$. The collagen content in the infarcted area was not measured in this study. However, we observed no increase in cardiac deaths in the T4 treated group during the early stage of post-MI remodeling, indicating that T4 treatment did not significantly interfere with the scar formation process.

Matrix metalloproteinases (MMPs) and tissue inhibitors of metalloproteinases (TIMPs) are critical in extracellular matrix remodeling by degrading certain components, regulating cell proliferation, migration, differentiation, and apoptosis as well as angiogenesis. More specifically, studies have shown that MMP-2 promotes angiogenesis by releasing angiogenic factors from the matrix, while TIMPs -1 to -3 can inhibit vascular endothelial cell migration and/or angiogenesis through releasing anti-angiogenic factors from matrix or interacting with angiogenic growth factor receptors [31,32]. With regard to cardiomyocyte hypertrophic remodeling, TIMPs -1 and -3 have been shown to exhibit an

Table 9 Collagen content in LV non-infarcted area

\begin{tabular}{llc}
\hline & N & Collagen content (\%) \\
\hline Sham & 6 & $1.8(0.6)$ \\
Ml & 5 & $2.9(0.8)^{*}$ \\
Ml+T4 & 5 & $2.3(0.9)$ \\
\hline
\end{tabular}

Data presented as means (SD). N, total number of rats.

$*, p<0.05$ vs. Sham operated rats;

ANOVA with Student-Newman-Keuls' Multiple Comparison Test. 


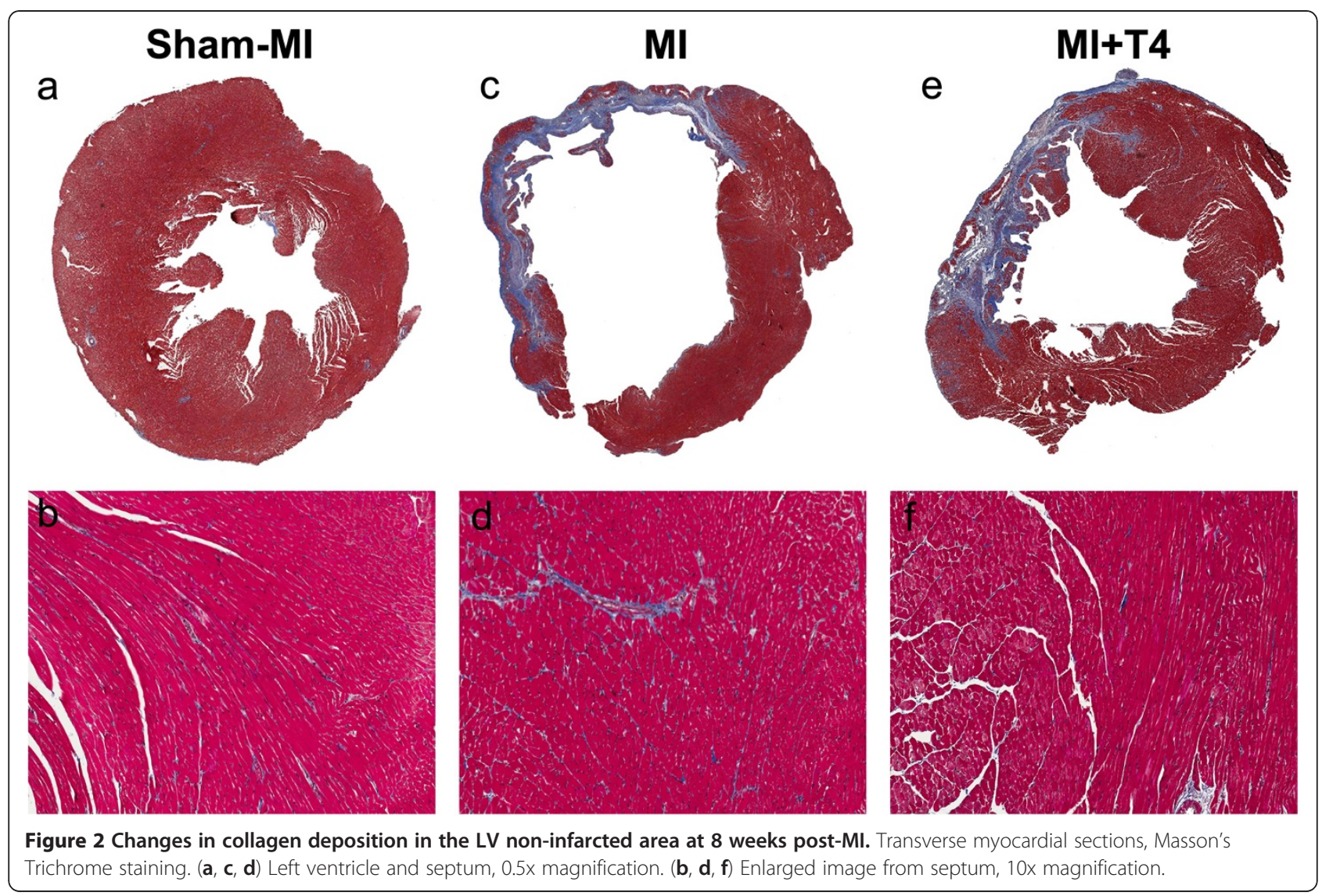

inhibitory effect [33-35]. Little is known about the role of TIMP-4 on cardiac remodeling besides its inhibitory effects on MMPs. The expression of MMPs and TIMPs following MI has a temporal and spatial pattern, where in the post-MI late stage, MMP-2 expression in the remote and border zone varied in different studies, TIMPs -1 to -3 expression was reduced in both remote and border zone, and TIMP-4 was unchanged in the remote myocardium but decreased in the border area [36-39]. In the present study, there was a tendency for increased MMP-2 and TIMPs -1 to -3 expression in the non-infarcted myocardium (includes both remote and border zone) late after MI. With T4 treatment, there was a tendency for further increase in MMP-2 expression but a decrease in TIMPs -1 to -4 expressions in the above-mentioned area. The difference in the findings of MMP-2 and TIMPs expression in these MI studies might be due to animal model differences and different methods of tissue sampling. No report can be found regarding the effects of THs on MMPs and TIMPs expression in the non-infarcted area during late stage postMI LV remodeling. However, Ziegelhoffer-Mihalovicova et al. reported that T3-induced cardiac hypertrophy was not accompanied by cardiac fibrosis but an increase in MMP-2 and TIMP-2 expression [40]. Ghose Roy et al. found a reduction in collagen I and III in cardiac tissue with an increase in MMP-1 activity and a decrease in TIMP-3 and TIMP-4 expression in T3-induced cardiac hypertrophy [30]. Thus, the long-term effects of T4 on myocyte remodeling and arteriolar growth in the noninfarcted area following MI might also relate to its actions on the expression of MMPs and TIMPs, which requires additional investigation to verify.

A number of animal studies in recent years have demonstrated a decline in tissue T3 levels after MI due to increased cardiac expression of the D3 deiodinase, which converts T4 to rT3 and T3 to T2 [41,42]. A report

Table 10 Fold changes in the expression of genes by RT-PCR

\begin{tabular}{lcc}
\hline Gene symbol & MI vs. Sham & MI+T4 vs. MI \\
\hline aMHC & 0.60 & 1.17 \\
BMHC & 2.58 & 0.19 \\
MMP-2 & 1.60 & 1.76 \\
TIMP-1 & 2.29 & 0.32 \\
TIMP-2 & 2.13 & 0.25 \\
TIMP-3 & 1.91 & 0.67 \\
TIMP-4 & 1.17 & 0.50 \\
\hline
\end{tabular}


showing worse outcomes in post-MI patients with elevated serum rT3 levels suggests a similar process occurs in humans [43]. Based on this finding, one might expect $\mathrm{T} 3$, rather than $\mathrm{T} 4$, to be more effective in restoring cardiac tissue T3 levels post-MI. While the increase was not statistically significant, serum T3 levels were 32\% higher in T4-MI rats compared to MI or sham groups. This trend suggests that peripheral conversion of T4 to T3 occurred as a result of elevated serum T4 and likely provided additional T3 for cardiac myocyte uptake.

Regulation of intracellular T3 is a complex process involving availability of free T3 in serum, as well as thyroid hormone membrane transporters and intracellular thyroid hormone binding proteins in the target cells. There is currently no information available regarding changes in thyroid membrane transporters and intracellular thyroid binding proteins in heart disease. Nonetheless, improvements in cardiac remodeling and function observed here suggest increased availability of T3 in the myocytes of treated rats. Now that important cardiac benefits of "supraphysiological" doses of THs post-MI have been demonstrated here and previously [12], a critical question remains unanswered. Can the functional and remodeling benefits of T3 or T4 treatment of MI be safely and effectively implemented in patients without adverse effects?

$\mathrm{TH}$ signaling is a complex and poorly understood process involving genomic and non-genomic signaling mechanisms [44]. Genomic signaling involves T3 binding to thyroid nuclear receptors associated with the thyroid response element of targeted genes. Involvement of many thyroid receptor isoforms, co-activators, and corepressors contribute to the complexity of genomic signaling. Many signaling pathways have been implicated in non-genomic TH signaling, including MAP kinases, PKC, and Akt. Work from our lab has identified a particularly important role for Akt signaling in myocyte and vascular remodeling [45-47].

\section{Conclusions}

T4 treatment of rats with MI led to significant improvement in LV function. The current study also used combined whole tissue and isolated myocyte preps to investigate myocyte remodeling from $\mathrm{T} 4$ treatment of MI. Myocyte shape improved but accounted for only $1 / 3$ of the T4-induced increase in muscle mass, suggesting improved myocyte survival. T4 treatment led to increased thickness of the non-infarcted and infarcted segment length, changes that should reduce wall stress. Small arterioles increased in proportion to muscle mass, suggesting $\mathrm{T} 4$ induction of physiologic vascular growth. There was also a trend toward reduced LV fibrosis with treatment. This study provides further evidence suggesting potential benefits from $\mathrm{TH}$ treatment of MI.
Competing interests

The authors declare that they have no competing interests.

\section{Authors' contributions}

YFC was the Project leader and performed surgeries, collected hemodynamic measurements, sample collection, data collection, statistical analysis, and manuscript preparation. NYW conducted arterial quantification and PCR. XL collected LV perimeter and tissue area measurements. SY conducted ELISA assays. DK collected comprehensive myocyte measurements. All work was conducted in the laboratory of AMG under his supervision. All authors read and approved the final manuscript.

\section{Acknowledgments}

These studies were supported by National Institutes of Health (NIH) RO1 HL093160-01A1 and R01 HL103671-01A1, as well as American Heart Association (AHA) MWA Fall 09 Postdoctoral Fellowship 10POST2650057.

\section{Author details}

${ }^{1}$ Department of Biomedical Sciences, NYIT College of Osteopathic Medicine, New York Institute of Technology, Old Westbury, NY 11568, USA. ${ }^{2}$ Sanford School of Medicine/University of South Dakota, Sioux Falls, SD 57105, USA. ${ }^{3}$ Department of Internal Medicine, Mount Vernon Hospital, Mount Vernon, NY 10550, USA.

Received: 10 November 2012 Accepted: 7 February 2013 Published: 14 February 2013

\section{References}

1. Pfeffer MA, Braunwald E: Ventricular remodeling after myocardial infarction. Experimental observations and clinical implications. Circulation 1990, 81:1161-1172.

2. Braunwald E, Pfeffer MA: Ventricular enlargement and remodeling following acute myocardial infarction: mechanisms and management. Am J Cardiol 1991, 68:1D-6D.

3. Sutton $M G$, Sharpe N: Left ventricular remodeling after myocardial infarction: pathophysiology and therapy. Circulation 2000, 101:2981-2988.

4. Zimmer HG, Gerdes AM, Lortet S, Mall G: Changes in heart function and cardiac cell size in rats with chronic myocardial infarction. $J \mathrm{Mol}$ Cell Cardiol 1990, 22:1231-1243.

5. Gerdes AM, Kellerman SE, Moore JA, Muffly KE, Clark LC, et al: Structural remodeling of cardiac myocytes in patients with ischemic cardiomyopathy. Circulation 1992, 86:426-430.

6. Lymvaios I, Mourouzis I, Cokkinos DV, Dimopoulos MA, Toumanidis ST, et al: Thyroid hormone and recovery of cardiac function in patients with acute myocardial infarction: a strong association? Eur J Endocrinol 2011, 165:107-114.

7. Ojamaa K, Kenessey A, Shenoy R, Klein I: Thyroid hormone metabolism and cardiac gene expression after acute myocardial infarction in the rat. Am J Physiol Endocrinol Metab 2000, 279:E1319-E1324.

8. Olivares EL, Marassi MP, Fortunato RS, da Silva AC, Costa-e-Sousa RH, et al: Thyroid function disturbance and type 3 iodothyronine deiodinase induction after myocardial infarction in rats a time course study. Endocrinology 2007, 148:4786-4792.

9. Chen YF, Kobayashi S, Chen J, Redetzke RA, Said S, et al: Short term triiodoL-thyronine treatment inhibits cardiac myocyte apoptosis in border area after myocardial infarction in rats. J Mol Cell Cardiol 2008, 44:180-187.

10. Pantos C, Mourouzis I, Markakis K, Tsagoulis N, Panagiotou M, et al: Longterm thyroid hormone administration reshapes left ventricular chamber and improves cardiac function after myocardial infarction in rats. Basic Res Cardiol 2008, 103:308-318.

11. Henderson KK, Danzi S, Paul JT, Leya G, Klein I, et al: Physiological replacement of $\mathrm{T} 3$ improves left ventricular function in an animal model of myocardial infarction-induced congestive heart failure. Circ Heart Fail 2009, 2:243-252.

12. Pantos C, Mourouzis I, Tsagoulis N, Markakis K, Galanopoulos G, et al: Thyroid hormone at supra-physiological dose optimizes cardiac geometry and improves cardiac function in rats with old myocardial infarction. J Physiol Pharmacol 2009, 60:49-56.

13. Thomas TA, Kuzman JA, Anderson BE, Andersen SM, Schlenker EH, et al: Thyroid hormones induce unique and potentially beneficial changes in 
cardiac myocyte shape in hypertensive rats near heart failure. Am $J$ Physiol Heart Circ Physiol 2005, 288:H2118-H2122.

14. Tomanek RJ, Busch TL: Coordinated capillary and myocardial growth in response to thyroxine treatment. Anat Rec 1998, 251:44-49.

15. Breisch EA, White FC, Hammond HK, Flynn S, Bloor CM: Myocardial characteristics of thyroxine stimulated hypertrophy. A structural and functional study. Basic Res Cardiol 1989, 84:345-358.

16. Yao J, Eghbali M: Decreased collagen gene expression and absence of fibrosis in thyroid hormone-induced myocardial hypertrophy. Response of cardiac fibroblasts to thyroid hormone in vitro. Circ Res 1992, 71:831-839.

17. Yao J, Eghbali M: Decreased collagen mRNA and regression of cardiac fibrosis in the ventricular myocardium of the tight skin mouse following thyroid hormone treatment. Cardiovasc Res 1992, 26:603-607.

18. Selye $H$, Bajusz $E$, Grasso S, Mendell P: Simple techniques for the surgical occlusion of coronary vessels in the rat. Angiology 1960, 11:398-407.

19. Tamura T, Said S, Harris J, Lu W, Gerdes AM: Reverse remodeling of cardiac myocyte hypertrophy in hypertension and failure by targeting of the renin-angiotensin system. Circulation 2000, 102:253-259.

20. Gerdes AM, Moore JA, Hines JM, Kirkland PA, Bishop SP: Regional differences in myocyte size in normal rat heart. Anat Rec 1986, 215:420-426.

21. Cheng W, Kajstura J, Nitahara JA, Li B, Reiss K, et al: Programmed myocyte cell death affects the viable myocardium after infarction in rats. Exp Cell Res 1996, 226:316-327.

22. Adair TH, Wells ML, Hang J, Montani JP: A stereological method for estimating length density of the arterial vascular system. Am J Physiol 1994, 266:H1434-H1438.

23. Gay R, Gustafson TA, Goldman S, Morkin E: Effects of L-thyroxine in rats with chronic heart failure after myocardial infarction. Am J Physiol 1987, 253:H341-H346.

24. Gay RG, Graham S, Aguirre M, Goldman S, Morkin E: Effects of 10- to 12day treatment with L-thyroxine in rats with myocardial infarction. Am J Physiol 1988, 255:H801-H806.

25. Chen YF, Redetzke RA, Sivertson RM, Coburn TS, Cypher LR, et al: Postmyocardial infarction left ventricular myocyte remodeling: are there gender differences in rats? Cardiovasc Pathol 2011, 20:e189-e195.

26. Davis FB, Mousa SA, O'Connor L, Mohamed S, Lin HY, et al: Proangiogenic action of thyroid hormone is fibroblast growth factor-dependent and is initiated at the cell surface. Circ Res 2004, 94:1500-1506.

27. Litwin SE, Litwin CM, Raya TE, Warner AL, Goldman S: Contractility and stiffness of noninfarcted myocardium after coronary ligation in rats. Effects of chronic angiotensin converting enzyme inhibition. Circulation 1991, 83:1028-1037.

28. Jugdutt $\mathrm{BI}$, Joljart MJ, Khan Ml: Rate of collagen deposition during healing and ventricular remodeling after myocardial infarction in rat and dog models. Circulation 1996, 94:94-101

29. Edgren J, von Knorring J, Lindy S, Turto H: Heart volume and myocardial connective tissue during development and regression of thyroxineinduced cardiac hypertrophy in rats. Acta Physiol Scand 1976, 97:514-518.

30. Ghose Roy S, Mishra S, Ghosh G, Bandyopadhyay A: Thyroid hormone induces myocardial matrix degradation by activating matrix metalloproteinase-1. Matrix Biol 2007, 26:269-279.

31. Collen A, Hanemaaijer R, Lupu F, Quax PH, van Lent N, et al: Membranetype matrix metalloproteinase-mediated angiogenesis in a fibrincollagen matrix. Blood 2003, 101:1810-1817

32. Givvimani S, Tyagi N, Sen U, Mishra PK, Qipshidze N, et al: MMP-2/TIMP-2/ TIMP-4 versus MMP-9/TIMP-3 in transition from compensatory hypertrophy and angiogenesis to decompensatory heart failure. Arch Physiol Biochem 2010, 116:63-72.

33. Heymans S, Lupu F, Terclavers S, Vanwetswinkel B, Herbert JM, et al: Loss or inhibition of UPA or MMP-9 attenuates LV remodeling and dysfunction after acute pressure overload in mice. Am J Pathol 2005, 166:15-25.

34. Creemers EE, Davis JN, Parkhurst AM, Leenders P, Dowdy KB, et al: Deficiency of TIMP-1 exacerbates LV remodeling after myocardial infarction in mice. Am J Physiol Heart Circ Physiol 2003, 284:H364-H371.

35. Fedak PW, Smookler DS, Kassiri Z, Ohno N, Leco KJ, et al: TIMP-3 deficiency leads to dilated cardiomyopathy. Circulation 2004, 110:2401-2409.

36. Wilson EM, Moainie SL, Baskin JM, Lowry AS, Deschamps AM, et al: Regionand type-specific induction of matrix metalloproteinases in postmyocardial infarction remodeling. Circulation 2003, 107:2857-2863.
37. Vanhoutte $D$, Schellings M, Pinto $Y$, Heymans S: Relevance of matrix metalloproteinases and their inhibitors after myocardial infarction: a temporal and spatial window. Cardiovasc Res 2006, 69:604-613.

38. Podesser BK, Siwik DA, Eberli FR, Sam F, Ngoy S, et al: ET(a)-receptor blockade prevents matrix metalloproteinase activation late postmyocardial infarction in the rat. Am J Physiol Heart Circ Physiol 2001, 280:H984-H991.

39. Peterson JT, Li H, Dillon L, Bryant JW: Evolution of matrix metalloprotease and tissue inhibitor expression during heart failure progression in the infarcted rat. Cardiovasc Res 2000, 46:307-315.

40. Ziegelhoffer-Mihalovicova B, Briest W, Baba HA, Rassler B, Zimmer HG: The expression of mRNA of cytokines and of extracellular matrix proteins in triiodothyronine-treated rat hearts. Mol Cell Biochem 2003, 247:61-68.

41. Pol CJ, Muller A, Zuidwijk MJ, van Deel ED, Kaptein E, et al: Left-ventricular remodeling after myocardial infarction is associated with a cardiomyocyte-specific hypothyroid condition. Endocrinology 2011, 152:669-679.

42. Simonides WS, Mulcahey MA, Redout EM, Muller A, Zuidwijk MJ, et al: Hypoxia-inducible factor induces local thyroid hormone inactivation during hypoxic-ischemic disease in rats. J Clin Invest 2008, 118:975-983.

43. Friberg L, Drvota V, Bjelak AH, Eggertsen G, Ahnve S: Association between increased levels of reverse triiodothyronine and mortality after acute myocardial infarction. Am J Med 2001, 111:699-703.

44. Pantos C, Mourouzis I, Cokkinos DV: Rebuilding the post-infarcted myocardium by activating 'physiologic' hypertrophic signaling pathways: the thyroid hormone paradigm. Heart Fail Rev 2010, 15:143-154.

45. Kuzman JA, O'Connell TD, Gerdes AM: Rapamycin prevents thyroid hormone-induced cardiac hypertrophy. Endocrinology 2007, 148:3477-3484.

46. Kuzman JA, Vogelsang KA, Thomas TA, Gerdes AM: L-thyroxine activates Akt signaling in the heart. $J \mathrm{Mol}$ Cell Cardiol 2005, 39:251-258.

47. Chen J, Ortmeier SB, Savinova OV, Nareddy VB, Beyer AJ, et al: Thyroid hormone induces sprouting angiogenesis in adult heart of hypothyroid mice through the PDGF-Akt pathway. J Cell Mol Med 2012, 16:2726-2735.

doi:10.1186/1479-5876-11-40

Cite this article as: Chen et al.: Improvement of left ventricular remodeling after myocardial infarction with eight weeks

L-thyroxine treatment in rats. Journal of Translational Medicine 2013 11:40.

\section{Submit your next manuscript to BioMed Central and take full advantage of:}

- Convenient online submission

- Thorough peer review

- No space constraints or color figure charges

- Immediate publication on acceptance

- Inclusion in PubMed, CAS, Scopus and Google Scholar

- Research which is freely available for redistribution 